\title{
Lentivirus-mediated overexpression of suppressor of cytokine signaling-3 reduces neutrophilic airway inflammation by suppressing T-helper 17 responses in mice with chronic Pseudomonas aeruginosa lung infections
}

\author{
FENG-MING DING, XING-YI ZHANG, YU-QING CHEN, RUO-MIN LIAO, \\ GUO-GANG XIE, PENG-YU ZHANG, PING SHAO and MIN ZHANG

\begin{abstract}
Department of Respiratory Medicine, Shanghai General Hospital, Shanghai Jiao Tong University
\end{abstract} \\ School of Medicine, Shanghai 200080, P.R. China
}

Received March 13, 2017; Accepted January 8, 2018

DOI: $10.3892 /$ ijmm.2018.3417

\begin{abstract}
The aim of the present study was to explore the effect of overexpressed suppressor of cytokine signaling-3 (SOCS3) on T-helper (Th)17 cell responses and neutrophilic airway inflammation in mice with chronic Pseudomonas aeruginosa (PA) infections. SOCS3 expression was enhanced via the administration of tail vein injections of therapeutic lentivirus in mice with chronic PA lung infections. SOCS3 expression in the blood and lung tissue was assessed using reverse transcription-quantitative polymerase chain reaction (RT-qPCR) and western blot analysis. Total and differential cell numbers and myeloperoxidase levels in the bronchoalveolar lavage (BAL) fluid were assessed, as well as the number of bacterial colonies in the lungs. Histological analysis of lung tissue was performed using hematoxylin and eosin staining and phosphorylated-signal transducer and activator of transcription-3 (p-STAT3) expression was measured by western blot analysis and immunohistochemistry. The expression of STAT3 mRNA and retinoid-related orphan receptor $(\mathrm{ROR}) \gamma \mathrm{t}$ were measured by RT-qPCR. The percentage of interleukin (IL) $-17^{+}$cells among cluster of differentiation (CD) $4^{+}$cells was calculated using flow cytometry and levels of IL-17A and IL-6 were assessed by ELISA. The expression of SOCS3 was significantly increased in $\mathrm{CD} 4^{+} \mathrm{T}$ cells following lentivirus injection and the inflammation of neutrophilic airways was notably ameliorated. Enhanced SOCS3 expression was associated
\end{abstract}

Correspondence to: Dr Min Zhang, Department of Respiratory Medicine, Shanghai General Hospital, Shanghai Jiao Tong University School of Medicine, 100 Haining Road, Shanghai 200080, P.R. China

E-mail: mzhang74@163.com

Key words: Pseudomonas aeruginosa, lung infection, suppressor of cytokine signaling-3, signal transducer and activator of transcription-3, $\mathrm{T}$ helper 17 response with a significant decrease in the expression of p-STAT3 and ROR $\gamma \mathrm{t}$ in $\mathrm{CD}^{+} \mathrm{T}$ cells. Additionally, the percentage of $\mathrm{IL}-17^{+}$ cells among $\mathrm{CD}^{+} \mathrm{T}$ cells and the IL-17 contents in the BAL fluid were significantly decreased. Lentivirus-mediated overexpression of SOCS3 was revealed to ameliorate neutrophilic airway inflammation by inhibiting pulmonary Th17 responses in mice with chronic PA lung infections.

\section{Introduction}

Pseudomonas aeruginosa (PA) is a gram-negative bacteria that causes chronic lung infections in individuals with various chronic lung diseases, including cystic fibrosis (CF), bronchiectasis and chronic obstructive lung disease $(1,2)$. PA cells communicate in colonies via quorum sensing and assemble into multicellular biofilms (3). Through interactions with pulmonary epithelial cells, PA is resistant to various antimicrobials and is able to cause chronic infections and persistent neutrophilic inflammatory responses, which are followed by tissue damage, organ injury, respiratory failure and mortality $(4,5)$. To the best of our knowledge, at present there is no effective treatment against PA bacterial infections. Therefore, an effective anti-inflammatory therapy that combats PA-induced neutrophilic inflammation is urgently required.

A previous study reported that cluster of differentiation (CD) $4^{+} \mathrm{T}$ cells are associated with specific adaptive immune responses directed against PA antigens (6). T helper (Th)17 cells have been identified as a subset of $\mathrm{CD} 4^{+} \mathrm{T}$ cells, which predominately produce the cytokines interleukin (IL)-17A, IL-17F, IL-21, IL-22 and IL-26 (7). Th17 differentiation is triggered by transforming growth factor- $\beta$ and IL- $6(8,9)$ and is controlled by transcription factors, including retinoid-related orphan receptor (ROR)- $\alpha$, ROR- $\gamma$ and the signal transducer and activator of transcription 3 (STAT3) $(10,11)$. IL-17A is a critical mediator of neutrophil recruitment and activation via the CXC chemokine (12). IL-17A is also able to induce the expression of matrix metalloproteinases, which are associated with tissue destruction (13). Dubin and Kolls (14) demonstrated 
that IL-23 mediates inflammatory responses against PA lung infections in mice. Additionally, they revealed that IL-23 deficient mice had diminished levels of IL-17. These results indicate that Th17 cells and their secretions serve a crucial role in inflammatory signaling during PA infection.

The suppressors of cytokine signaling (SOCS) family are important for the negative feedback inhibition of cytokines (15). SOCSs are considered to be strong inhibitors of Janus kinases (JAKs), cytokine receptors and their downstream targets (16). A recent study indicated that SOCS3 is a promising negative regulator of Th17 differentiation and function (17). Additionally, Oshita et al (18) demonstrated that enhanced expression of SOCS3 significantly inhibited the differentiation of T cells into Th17 cells. Chen et al (19) confirmed that SOCS3 inhibited IL-23-mediated phosphorylation of STAT3 and thus prevented interactions between phosphorylated (p)-STAT3 and the promoters of IL-17A and IL-17F.

Based on these previous studies, it has been hypothesized that SOCS3 may serve a key role in IL-17 mediated neutrophilic airway inflammation during pulmonary PA infections. In the present study lentivirus was used to deliver SOCS3 in a well-established mouse model and PA lung infections were subsequently introduced. The effects of SOCS3 on pulmonary Th17 responses and airway inflammation were investigated.

\section{Materials and methods}

Recombination of SOCS3 lentiviral and cell transfection. In the present study a third generation lentiviral system, including pGLV-EF1a-green fluorescent protein (GFP) vector, pLV/helper-SL3 (gag/pol element), pLV/helper-SL4 (pRev element) and pLV/helper-SL5 (pVSVG element) plasmids (Shanghai GenePharma Co., Ltd., Shanghai, China) was used to construct lentiviruses for the overexpression of SOCS3. The lentivirus vectors with GFP were purchased from Shanghai GenePharma Co., Ltd. (Shanghai, China). According to the information provided by National Center for Biotechnology Information, the full length of the murine SOCS3 gene (NM_007707.3) was screened and accurately inserted into the pGLV-EF1a-GFP plasmid using polymerase chain reaction (PCR) technology and DNA sequencing. Subsequently, plasmids [pLV/helper-SL3, pLV/helper-SL4, pLV/helper-SL5, and pGLV-EF1a-GFP-SOCS3 or pGLV-EF1a-GFP (negative control)] were co-transfected into $293 \mathrm{~T}$ cells using Lipofectamine $^{\mathrm{TM}} 2000$ (Invitrogen; Thermo Fisher Scientific, Inc., Waltham, MA, USA). At 12 h later, the 293T culture medium was replaced with fresh Dulbecco's Modified Eagle Medium (DMEM; Thermo Fisher Scientific, Inc.) containing $10 \%$ fetal bovine serum (FBS, Thermo Fisher Scientific, Inc.). The lentivirus of SOCS3 and the negative control were harvested with DMEM containing 10\% FBS $48 \mathrm{~h}$ following transfection. Following centrifugation at $4^{\circ} \mathrm{C} 750,000 \mathrm{x}$ g for $90 \mathrm{~min}$, the products were diluted to varying concentrations $\left(10^{-1}-10^{-4}\right)$ and used to infect fresh $293 \mathrm{~T}$ cells. The efficiency of 293 T infections was assessed according to the number of GFP positive cells using a fluorescence microscope (magnification, $\mathrm{x} 400$ ). The formula used to calculate virus titer was as follows: Lentivirus titer [transducing units $(\mathrm{TU}) / \mathrm{ml}$ ] = GFP positive cell number $\mathrm{x}$ dilution times/volume of lentivirus.
Construction of a chronic PA lung infected mouse model. A total of 36 female C57/BL/6 specific pathogen-free mice, 20-35 g and aged 8-12 weeks, were purchased from Shanghai SLAC laboratory Animal Co. Ltd. (Shanghai, China). The mice were housed in a temperature-controlled room $\left(23^{\circ} \mathrm{C}\right.$ and $\sim 45 \%$ humidity) with $12 \mathrm{~h}$ light/dark cycle and fed a standard mouse diet and water with free access. PA cells (American Type Culture Collection 27863) were purchased from China General Microbiological Culture Collection Centre (Beijing, China) and embedded in agarose beads at a final concentration of $2.0 \times 10^{6}$ colony-forming units (CFU)/50 $\mu \mathrm{l}$ PBS as previously described (20). Following anesthesia, a total of $50 \mu \mathrm{l}$ of PA-laden agarose beads were injected into the right lung of each mouse. Experiments were performed according to the guidelines for the Care and Use of Laboratory Animals and the mortality rate during this procedure was $10 \%$. All experiments were approved by the Institution of Animal Care and Use Committee of Shanghai Jiao Tong University School of Medicine (Shanghai, China).

Lentivirus therapy in vivo. To avoid the increased mortality associated with a single tail vein injection of a high dose of lentivirus, the doses were divided into several injections of smaller doses and the effects were investigated 3 days following the establishment of the mouse model. In the present study 6 injections of $3.3 \times 10^{7}$ TU were administered over $12 \mathrm{~h}$ (a total of $2 \times 10^{8} \mathrm{TU} /$ mouse). A total of 36 mice were randomly allocated into 3 groups (12 mice/group) and treated as follows: i) Blank control group, treated with the same volume of PBS; ii) negative control group, treated with pGLV-EF1a-GFP and iii) lentivirus LV-SOCS3 group, treated with pGLV-EF1a-GFP-SOCS3. The weight, central and peripheral skin color, respiratory rate and movement of mice were recorded daily. At $0,4,24$, and $72 \mathrm{~h}$ following lentivirus injection, the mice were euthanized 3 mice per time point) and peripheral blood, lung tissue and bronchoalveolar lavage (BAL) fluids were collected for subsequent analysis. To investigate the kinetic profiles of lentiviruses, RNA from blood cells and lung tissues was extracted using TRIzol reagent (Invitrogen; Thermo Fisher Scientific, Inc.). Lentivirus RNA expression levels were measured using reverse transcription-quantitative (RT-q) PCR and the number of lentivirus copies per genome $(\mathrm{C} / \mathrm{G})$ was evaluated using RT-qPCR using previously described primers and probes (21). Copies per genome $(\mathrm{C} / \mathrm{G})$ were computed using the following equation: (ng lentivirus DNA/ng endogenous DNA) $x$ (no. of lentivirus integrations in the standard curve).

Cell numbers in the BAL fluid. Following euthanasia, mouse tracheas were instilled multiple times with $1.8 \mathrm{ml}$ aliquots of aseptic PBS and the BAL fluid was subsequently retrieved. Following centrifugation at $4^{\circ} \mathrm{C}, 650 \mathrm{x} \mathrm{g}$ for $10 \mathrm{~min}$ the supernatants of the retrieved BAL fluids were sterile-filtered for cytokine analyses and the sediments were resuspended in PBS. Leukocyte cell numbers were measured using a hemocytometer and the numbers of neutrophils and lymphocytes were quantified using a minimum of 100 consecutive hematoxylin and eosin (H\&E)-stained cells. Cell counting experiments were conducted blindly and independently by two experienced pathologists. 
Bacterial load evaluation. To quantify the number of bacteria, the right middle lung lobes were harvested from sacrificed mice and homogenized in saline solution. Serial dilutions were subsequently cultured on sheep blood agar plates (BioTrading, Mijdrecht, The Netherlands) overnight at $37^{\circ} \mathrm{C}$. The bacterial colonies from the lung lobes of each mouse were counted.

Histology. Following fixing with $10 \%$ neutral-buffered formalin at $4^{\circ} \mathrm{C}$ for $24-48 \mathrm{~h}$, tissues were embedded in paraffin and cut into slices $(5 \mu \mathrm{m})$. Sections of the right lower lobes were stained with hematoxylin and eosin. Ten fields of each mouse were analyzed using a light microscope at low power (magnification, $\mathrm{x} 40$ ) by two independently blinded pathologists. Each section was scored using the following criteria: i) For intraluminal infiltrates, none positive scored 0 points, $<25 \%$ positive lumens scored 1 point, $25-50 \%$ positive lumens scored 2 points, $50-75 \%$ positive lumens scored 3 points and diffuse staining scored 4 points; ii) For peribronchial infiltrates, none positive scored 0 points, positive area $\leq 4$ cells thickness scored 1 point, positive area 5-10 cells thickness scored 2 points, positive areas $>10$ cells thickness but $\leq 50 \%$ of visualized lumens scored 3 points and diffuse cell areas scored 4 points; iii) For alveolar involvement, no positive cells scored 0 points, increased cellular characteristics scored 1 point, interlobular septal thickening scored 2 points, obliteration $\leq$ a quarter of the visualized alveolar spaces scored 3 points and obliteration $>$ a quarter of the visualized alveolar spaces scored 4 points.

Myeloperoxidase (MPO) and cytokine analysis in BAL fluids. Quantikine ${ }^{\circledR}$ ELISA kits (R\&D Systems, Inc., Minneapolis, MN,USA) were purchased for assays of MPO (cat.no.DY3667), IL-6 (cat. no. M6000B), IL-8 (cat. no. MAB16081) and IL-17A (cat. no. M1700) in the BAL fluids. Each assay was performed twice according to manufacturer's protocol and the mean values were calculated.

Isolation of lung $\mathrm{CD}^{+} \mathrm{T}$ cells. Following homogenizing in $0.5 \mathrm{ml}$ normal saline, the lung tissues were digested using trypsin and filtered through a $40-\mu$ m nylon mesh. Subsequently, CD4 ${ }^{+}$ $\mathrm{T}$ cell isolation kits and Mini-MACS ${ }^{\mathrm{TM}}$ columns (both Miltenyi Biotec, Inc., Auburn, CA, USA) were used to isolate CD4 ${ }^{+} \mathrm{T}$ cells according to manufacturer's protocol following centrifugation at $4^{\circ} \mathrm{C}, 1,100 \mathrm{x} \mathrm{g}$ for $10 \mathrm{~min}$ and three washes with PBS.

RT-qPCR assay for RNAs in $C D 4^{+} T$ cells. Total RNA from lung $\mathrm{CD}^{+}{ }^{+} \mathrm{T}$ cells was extracted using TRIzol reagent (Thermo Fisher Scientific, Inc.) and RNA was reverse transcribed into cDNA using the Primer-ScriptTM one step RT-PCR kit (Takara Bio, Inc., Otsu, Japan) according to manufacturers' protocols. PCR was performed using the following primers and probe sequences: Mouse SOCS3 sense, 5'-CTGCAGGAGAGCGGA TTCTACT-3' and antisense, 5'-GCTGTCGCGGATAAGAAA GG-3'; mouse SOCS3 probe, 5'-CTGCTGCTCAGCGCCGAG CC-3'; mouse STAT3 sense, 5'-GGGCCAGGCCAACCA-3' and antisense, 5'-CCGGACATCCTGAAGATGCT-3'; mouse STAT3 probe, 5'-CCAACAGCCGCCGTAGTGACAGAG T-3'; mouse ROR $\gamma$ t sense, 5'-TCTCTGCAAGACTCATCG ACAAG-3' and antisense, 5'-GCACAGGCTCCGGAGTTT T-3'; mouse ROR $\gamma$ t probe, 5'-CTCCTAGCCAAGCTGCCA
CCCAAA-3'. PCR was performed on a LightCycler ${ }^{\circledR}$ (Roche Diagnostics, Indianapolis, IN, USA) using 2X SYBR-Green (Takara Bio, Inc.) according to manufacturer's protocol with the following system: $95^{\circ} \mathrm{C}$ for $3 \mathrm{~min}$ and 40 cycles of $95^{\circ} \mathrm{C}$ for $10 \mathrm{sec}$ and $55^{\circ} \mathrm{C}$ for $30 \mathrm{sec}$. The expression levels of the target genes were normalized to the internal control $\beta$-actin using the $2^{-\Delta \Delta \mathrm{Cq}}$ method (22).

Western blot analysis. Proteins from $\mathrm{CD} 4^{+} \mathrm{T}$ cells were extracted using a Nuclear and Cytoplasmic Protein Extraction kit (Beyotime Institute of Biotechnology, Haimen, China) and protein concentrations were evaluated using a BCA protein assay. A total of $50 \mu \mathrm{g}$ aliquots of protein samples were mixed with a loading buffer and boiled for $10 \mathrm{~min}$. Proteins $(15 \mu \mathrm{g})$ were separated by $10 \%$ SDS-PAGE. Proteins were transferred onto polyvinylidene fluoride membranes and blocked with $5 \%$ non-fat milk at room temperature for $1 \mathrm{~h}$. The membranes were subsequently incubated with rabbit anti-mouse SOCS3 polyclonal antibodies (1:500; cat.no. sc-9023) rabbit anti-mouse $\beta$-actin polyclonal antibodies $(1: 1,000$; cat. no. sc-58673; both Santa Cruz Biotechnology, Inc., Dallas, TX, USA) or rabbit anti-mouse p-STAT3 monoclonal antibodies (1:2,000; cat. no. 9145; Cell Signaling Technology, Inc., Danvers, MA, USA) at $4^{\circ} \mathrm{C}$ overnight. The membranes were subsequently washed and incubated with horseradish peroxidase (HRP)-conjugated secondary antibodies (1:5,000; cat. no. 111035144; Jackson ImmunoResearch Laboratories, Inc., West Grove, PA, USA) at room temperature for $1 \mathrm{~h}$. The protein bands were illuminated using the enhanced chemiluminescence method (GE Healthcare Life Sciences, Little Chalfont, UK), and quantified by densitometry analyses using Quantity One software version 4.6.1 (Bio-Rad Laboratories, Inc., Hercules, CA, USA) using $\beta$-actin as the internal reference.

Immunohistochemistry (IHC) detection of activated STAT3 in lung tissues. Following deparaffinization and rehydrated in a graded series of alcohol, and antigen retrieval was performed by microwaving $(650 \mathrm{~W})$ for $10 \mathrm{~min}$ in sodium citrate buffer (pH 6.0). Endogenous peroxidase activity was blocked with $3 \%$ hydroperoxidase at room temperature for $20 \mathrm{~min}$ and the sections were subsequently incubated with rabbit anti-mouse p-STAT3 antibodies (1:400; cat. no. 9145) at $4^{\circ} \mathrm{C}$ overnight followed by HRP-conjugated secondary antibodies $(1: 1,000$; cat. no. 111035144; Jackson ImmunoResearch Laboratories, Inc.) at room temperature for $30 \mathrm{~min}$ and then colorized using a 3,3'-diaminobenzidine substrate solution. Finally, sections were counterstained with hematoxylin at room temperature for 3-5 min to visualize the nuclei and analyzed by two independently blinded pathologists using a light microscope (magnification, $\mathrm{x} 40$ ).

Flow cytometric analyses of $\mathrm{CD}^{+}$and $\mathrm{IL}-17^{+}$cells in the lungs. $\mathrm{CD}^{+}$cells derived from lung tissue were permeabilized in $0.2 \%$ Triton X-100 and incubated with allophycocyanin (APC)-conjugated IL-17 antibodies (1:200; cat. no. 45717782, eBioscience; Thermo Fisher Scientific, Inc.) in a final volume of $100 \mu \mathrm{l}$ buffer [PBS, pH 7.4 with $1 \%$ bovine serum albumin (Thermo Fisher Scientific, Inc.)] overnight at $4^{\circ} \mathrm{C}$. The cells were subsequently washed 3 times in PBS and analyzed using a FACSCalibur ${ }^{\mathrm{TM}}$ flow cytometer (Becton-Dickinson; 
A

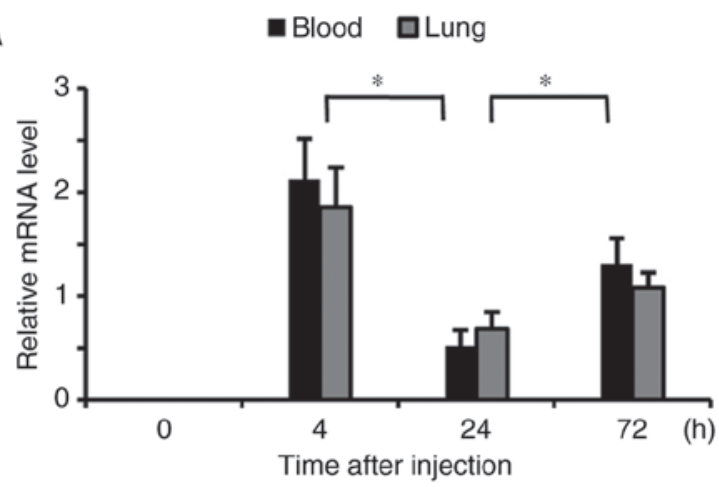

B

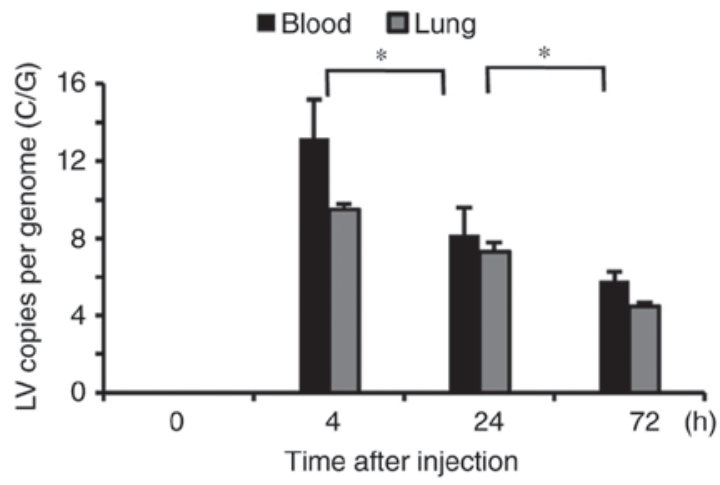

Figure 1. Kinetic profile of LV contents in the blood and lung tissue following intravenous injections. (A) Quantification of green fluorescent protein LV RNA in the blood and lung tissue following injection. (B) The LV DNA in the blood and lung tissues was quantified and the lentivirus copies per genome were analyzed. $\mathrm{n}=3$. ${ }^{*} \mathrm{P}<0.05 \mathrm{LV}$, lentivirus.

BD Biosciences) in the FL4 channel. Background fluorescence was assessed using a non-specific rat immunoglobulin $G$ (eBioscience; Thermo Fisher Scientific, Inc.).

Statistical analysis. All data were analyzed using SAS version 8.1 statistical software (SAS Institute, Inc., Cary, NC, USA). Normality analysis was conducted by a Shapiro-Wilk test. Data are presented as the mean \pm standard error of the mean and differences were identified using analysis of variance. Non-parametric data were analyzed using a Mann-Whitney $\mathrm{U}$ test with a Bonferroni correction. $\mathrm{P}<0.05$ was considered to indicate a statistically significant difference.

\section{Results}

Kinetic profiles of lentivirus. Transfected kinetics were investigated using RT-qPCR following six injections of lentivirus. Notably increased levels of lentivirus were detected in the blood and lung tissues $4 \mathrm{~h}$ following transfection and they significantly decreased at $24 \mathrm{~h}(\mathrm{P}<0.05$; Fig. 1A). However, at $72 \mathrm{~h}$ following transfection the lentivirus RNA levels in the blood and lung tissues were again significantly elevated $(\mathrm{P}<0.05)$ compared with $24 \mathrm{~h}$, but to a smaller degree that at $4 \mathrm{~h}$. The number of lentivirus $\mathrm{C} / \mathrm{G}$ was significantly increased in the blood and lung tissues at $4 \mathrm{~h}$ following the injection, but markedly decreased at 24 and $72 \mathrm{~h}$ compared with their previous time points $(\mathrm{P}<0.05$; Fig. $1 \mathrm{~B})$.

SOCS3 gene overexpression in alveolar $C D 4^{+}$T cells following lentivirus injection. SOCS3 expression in lung $\mathrm{CD}^{+} \mathrm{T}$ cells was confirmed by RT-qPCR and western blot analysis. The relative mRNA expression of SOCS3 in the LV-SOCS3 group was significantly increased compared with the blank and negative control groups (both $\mathrm{P}<0.05$ ); however, no notable differences in SOCS3 mRNA expression were observed between the blank and negative control groups (Fig. 2A). Western blot analyses revealed a significantly higher SOCS3 expression in the LV-SOCS3 group compared with the blank or negative control groups (both $\mathrm{P}<0.05$; Fig. $2 \mathrm{~B}$ and $\mathrm{C}$ ).

Overexpression of SOCS3 inhibits neutrophil airway infiltration but does not affect the bacterial load. Following treatment with lentivirus, the severity of dyspnea and weight loss in the LV-SOCS3 group was significantly reduced compared with the blank and negative control groups (data not shown). However, the leukocyte cell number was significantly reduced in the BAL fluids of the LV-SOCS3 group compared with the blank and negative control groups $(\mathrm{P}<0.05$; Fig. 3A). Similarly, the percentage of neutrophils in the BAL fluid was also significantly reduced in the LV-SOCS3 group compared with the blank and negative control groups $(\mathrm{P}<0.05$; Fig. 3B), however, the percentages of lymphocytes was only marginally increased (Fig. 3C). Additionally, ELISA analysis revealed significantly lower levels of MPO in the BAL fluid of the LV-SOCS3 group compared with the blank and negative control groups $(\mathrm{P}<0.05$; Fig. 3D). No notable differences were observed between the blank and negative control groups in any of the categories listed above.

In pathological assessments of mice from the presented treatment groups, $H \& E$ staining analyses revealed that the pathological condition in the LV-SOCS3 group was less severe than in the blank and negative control groups (Fig. 4A). This indicates reduced airway inflammation and fewer neutrophils present in the LV-SOCS3 group. Histology scores of the images revealed a significantly lower intraluminal infiltration, peribronchial infiltration, and alveolar hemorrhage in the LV-SOCS3 group compared with blank and negative control groups $(\mathrm{P}<0.05$; Fig. 4B). The bacterial loads (x10 $4 \mathrm{CFU} / \mathrm{g}$ lung tissue) did not significantly differ between the LV-SOCS3 group (3.10 \pm 0.56$)$, the blank $(2.80 \pm 0.78)$ and negative control $(2.50 \pm 0.96)$ groups (data not shown).

Overexpression of SOCS3 decreases p-STAT3 in pulmonary $C D 4^{+} T$ cells. To investigate the mechanism of SOCS3, p-STAT3 expression was detected by IHC. Significantly fewer p-STAT3 positive cells were observed in the LV-SOCS3 group compared with the blank and negative control groups $(\mathrm{P}<0.05$; Fig. 5A). To further explore whether SOCS3 directly regulates p-STAT3 in alveolar CD4 ${ }^{+}$positive cells, the mRNA level of SOCS3 was measured. These experiments demonstrated a significantly lower expression of STAT3 in CD4 $4^{+}$cells from the LV-SOCS3 group compared with those from the blank and negative control groups $(\mathrm{P}<0.05$; Fig. 5B). p-STAT3 protein levels were significantly downregulated in the LV-SOCS3 group compared with the blank and negative control groups $(\mathrm{P}<0.05$; Fig. 5C and $\mathrm{D})$. 
A

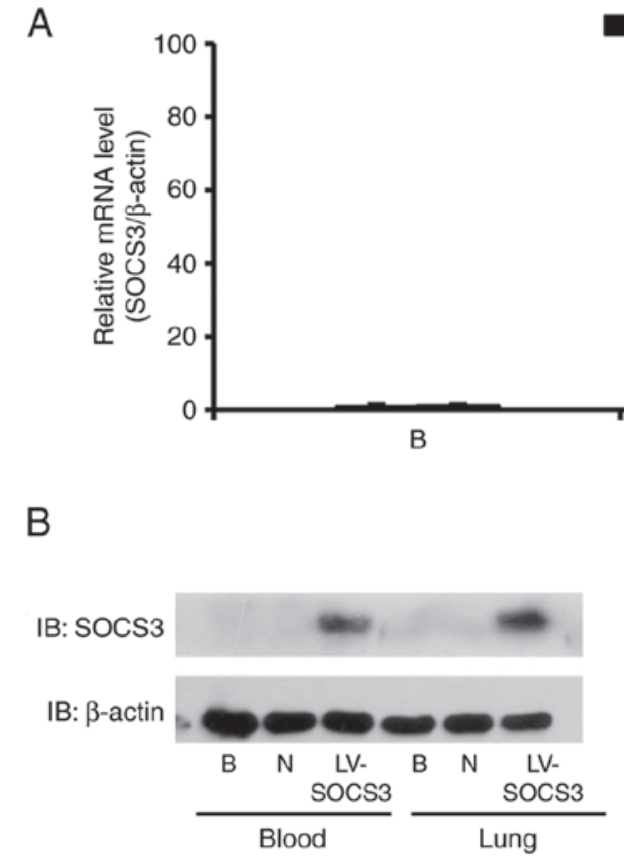

\section{B}

Blood

Lung
C

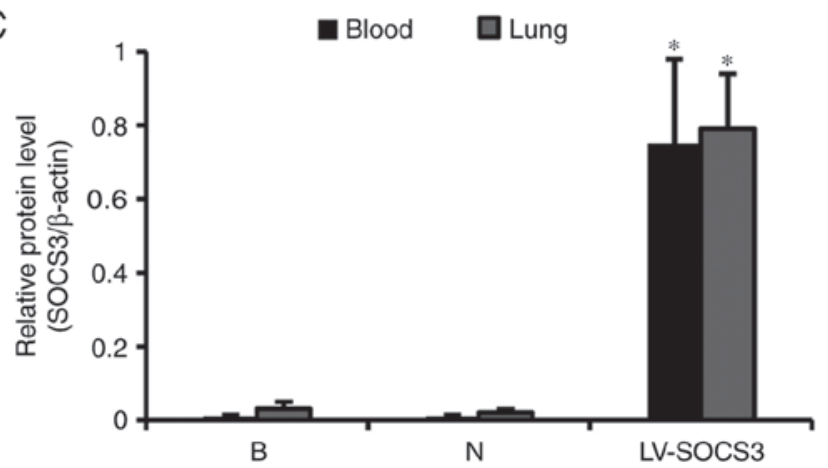

Figure 2. SOCS3 gene expression in pulmonary $\mathrm{CD}^{+} \mathrm{T}$ cells following lentivirus injection $72 \mathrm{~h}$ later. (A) Reverse transcription-polymerase chain reaction analyses of SOCS3 expression in the different groups. (B) Western blot analyses of SOCS3 expression in the different groups. (C) Quantification of SOCS3 protein levels in the different groups. $\mathrm{n}=12$ ( 3 per time point). ${ }^{*} \mathrm{P}<0.05$ SOCS3, suppressor of cytokine signaling protein 3 ; $\mathrm{CD}$, cluster of differentiation; $\mathrm{B}$, blank control group; N, negative control group; LV-SOCS3, lentiviral vector-mediated SOCS3 group.
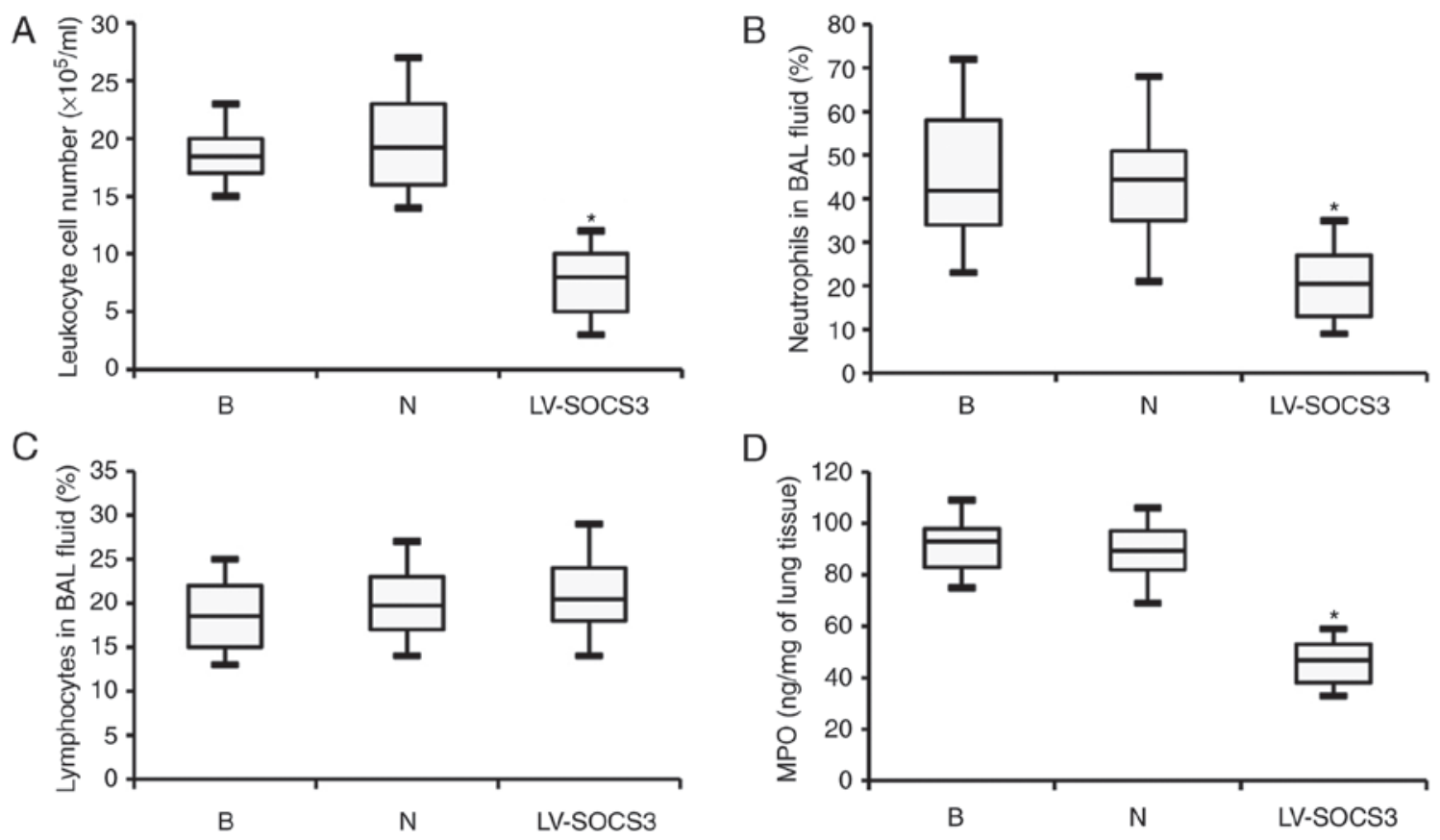

Figure 3. Cell numbers and MPO expression in mice with chronic Pseudomonas aeruginosa lung infections and lentivirus injection $72 \mathrm{~h}$ later. (A) Total cell numbers were calculated in BAL fluid. The percentage of (B) neutrophils and (C) lymphocytes were measured in the BAL fluid. (D) The amount of MPO in the lung tissue was also measured by ELISA. $\mathrm{n}=3$. " $\mathrm{P}<0.05$ vs. the $\mathrm{B}$ and $\mathrm{N}$ groups MPO, myeloperoxidase; BAL, bronchoalveolar; $\mathrm{B}$, blank control group; $\mathrm{N}$, negative control group; LV-SOCS3, lentiviral vector-mediated suppressor of cytokine signaling protein 3 group.

Overexpression of SOCS3 suppresses the pulmonary Th17 response via ROR $\gamma t$, IL-17A and IL-8. To evaluate the effect of the SOCS3 gene on pulmonary Th17 responses in the lung, the percentages of $\mathrm{CD} 4^{+} \mathrm{IL}-17^{+}$cells were measured using flow cytometry (Fig. 6A). The results revealed a markedly lower percentage of $\mathrm{CD} 4^{+} \mathrm{IL}-17^{+}$positive cells in 
A
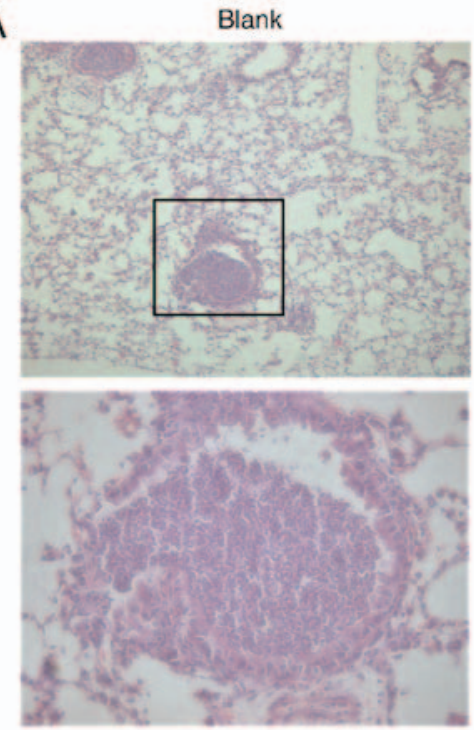

B

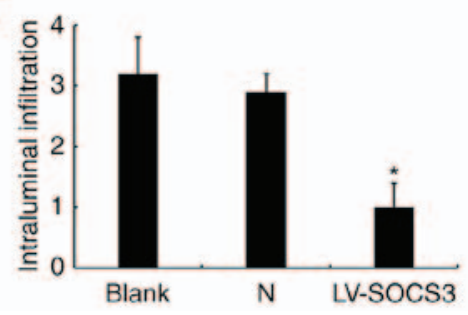

$\mathrm{N}$
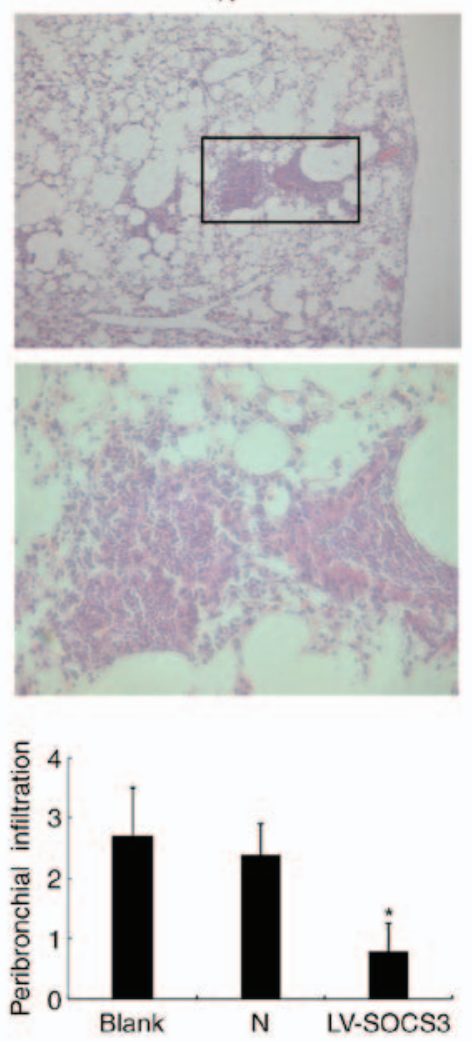

LV-SOCS3
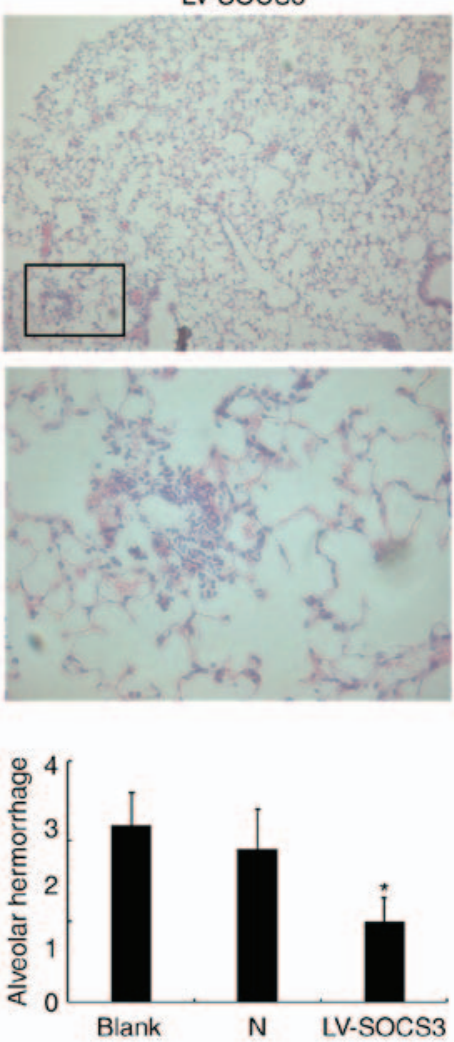

Figure 4. H\&E staining of lung tissue following the overexpression of SOCS3. (A) Representative images of the H\&E staining of lung tissue from the blank control group, negative control group and LV-SOCS3 group. The boxes in the upper image are enlarged in the image below. Upper image magnification, $\mathrm{x} 40$; scale bar, $500 \mu \mathrm{m}$. Lower image magnification, x400; scale bar, $50 \mu \mathrm{m}$. (B) Histology scores of the intraluminal infiltration, peribronchial infiltration and alveolar hemorrhage. $n=3$. " $\mathrm{P}<0.05$ vs. Blank group and ${ }^{*} \mathrm{P}<0.05$ vs. $\mathrm{N}$ group. H\&E, hematoxylin and eosin; SOCS3, suppressor of cytokine signaling protein 3 ; LV-SOCS3, lentiviral vector-mediated SOCS3 group; N, negative control group.

A

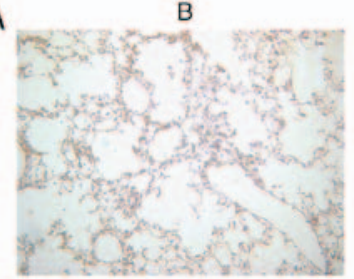

B

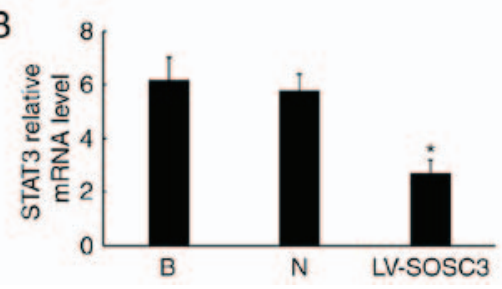

$\mathrm{N}$

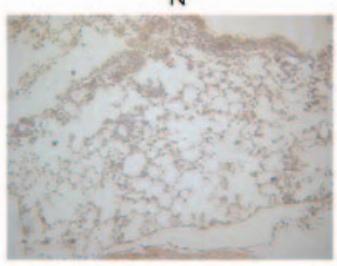

C
LV-SOSC3

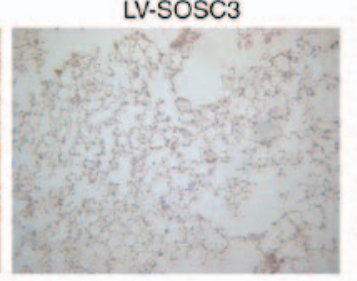

D

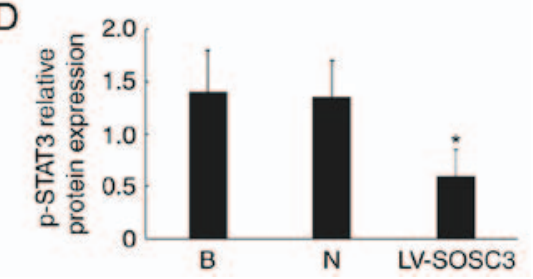

Figure 5. Expression and activation of STAT3 in pulmonary CD4+ $\mathrm{T}$ cells with overexpressed SOCS3. (A) Immunohistochemistry analyses of activated STAT3 were performed in the lung tissues from different groups (magnification, $\mathrm{x} 100$; scale bar, $200 \mu \mathrm{m}$ ) and the percentages of p-STAT3 positive cells were analyzed. (B) Relative STAT3 mRNA levels were determined in lung $\mathrm{CD} 4^{+} \mathrm{T}$ cells using reverse transcription-quantitative polymerase chain reaction. (C) Western blot analysis was performed to measure the levels of p-STAT3 in pulmonary CD4 ${ }^{+} \mathrm{T}$ cells and (D) these results were quantified. $\mathrm{n}=12$. ${ }^{*} \mathrm{P}<0.05$ vs. the B group and " $\mathrm{P}<0.05$ vs. the $\mathrm{N}$ groups. B, blank control group; N, negative control group; LV-SOCS3, lentiviral vector-mediated SOCS3 group; SOCS3, suppressor of cytokine signaling protein 3; STAT3, signal transducer and activator of transcription 3; CD, cluster of differentiation; p, phosphorylated.

the LV-SOCS3 group compared with the blank and negative control groups $(\mathrm{P}<0.05$; Fig. 6B). The levels of ROR $\gamma \mathrm{t}$, IL-17A, IL-8 and IL-6 mRNA were also measured, as they are important contributors to the pulmonary Th17 response. The results revealed significantly lower ROR $\gamma \mathrm{t}$ mRNA expression in the LV-SOCS3 group compared with the blank and negative control groups $(\mathrm{P}<0.05$; Fig. 6C). ELISA assays demonstrated significantly lower levels of IL-17A and IL-8 in the LV-SOCS3 group compared with the blank and negative groups $(\mathrm{P}<0.05$; Fig. 6D and E). No significant differences were identified in the expression of IL-6 were detected between the three groups (Fig. 6F). 


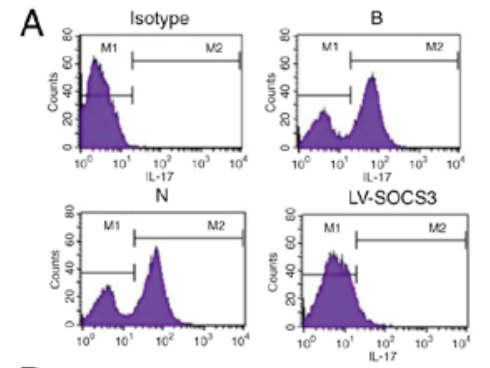

D

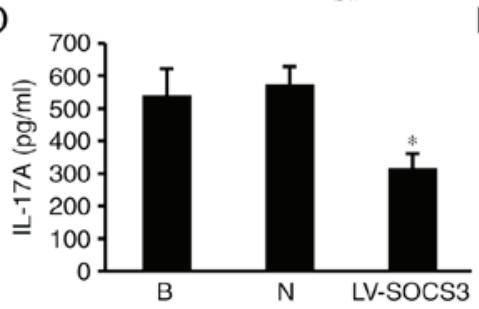

B

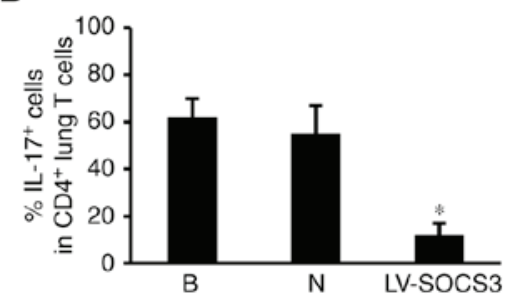

E

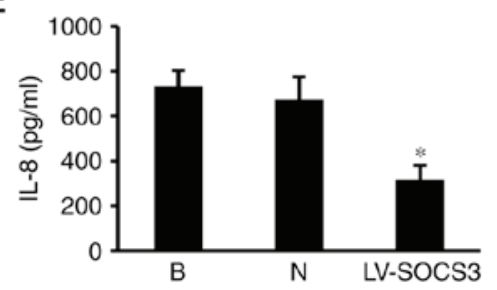

C

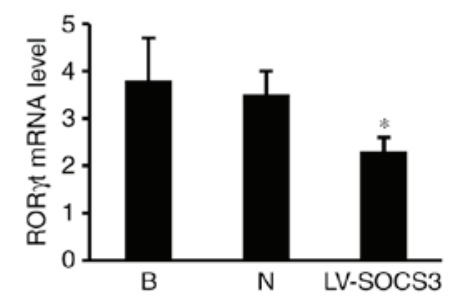

F

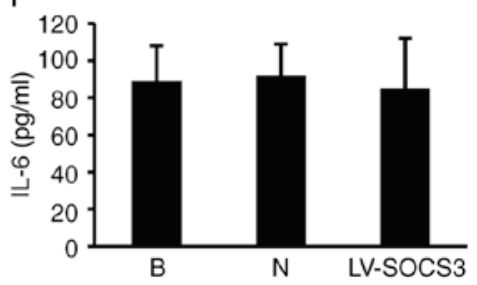

Figure 6. Th17 responses and cytokine production in the lung tissues. (A) Representative flow cytometric histograms of the presence of IL-17 in CD4 ${ }^{+}$cells. (B) The percentage of IL-17 $7^{+}$cells in pulmonary CD4 ${ }^{+} \mathrm{T}$ cells. (C) ROR $\gamma \mathrm{t}$ mRNA levels were determined in lung CD4 ${ }^{+} \mathrm{T}$ cells using reverse transcriptionquantitative polymerase chain reaction. (D) IL-17A, (E) IL-8 and (F) IL-6 mRNA in the BAL fluid were analyzed by ELISA. n=12/group. *P<0.05 vs. the $\mathrm{B}$ group and ${ }^{*} \mathrm{P}<0.05$ vs. the $\mathrm{N}$ groups. B, blank control group; N, negative control group; LV-SOCS3, lentiviral vector-mediated suppressor of cytokine signaling protein 3 transfer group; IL, interleukin; BAL, bronchoalveolar lavage fluid.

\section{Discussion}

As a member of the SOCS protein family, SOCS3 negatively regulates the cytokine signaling pathway (23) and may be induced by selected inflammatory cytokines (19). In the present study, SOCS3 expression was enhanced by lentivirus infection in mice with chronic PA lung infections and the ensuing effects were investigated. Overexpression of SOCS3 significantly suppressed pulmonary Th17 responses and neutrophilic infiltration by inhibiting the expression of ROR $\gamma \mathrm{t}$, IL-17A and IL-8 in pulmonary CD $4^{+} \mathrm{T}$ cells.

A previous study reported that SOCS3 serves a critical role in restricting inflammation and regulating protective immune responses against infection in multiple mouse models (24). A significant downregulation in airway inflammation with no concurrent change in bacterial load was observed in the present study following the lentivirus overexpression of SOCS3 in mice with chronic PA lung infection. Dubin and Kolls (14) previously eliminated Th17 responses by attenuating IL-23 expression, this also had no influence on the bacterial load and dissemination in mice with chronic PA lung infections. Additionally, IL-23 and IL-17 signaling has been confirmed as dispensable for the establishment of host mycobacteria, which are also prevalent opportunistic pathogens in patients with CF (25). It has been demonstrated that SOCS3 regulates STAT3-mediated chemokine and chemokine receptor interactions in the bone marrow and serves a crucial role in the neutrophil mobilization response (26). Taken together these results indicate that SOCS3 suppresses airway inflammation by aborting Th17 signal responses and that STAT3 is associated with this process. However, in the present study SOCS3 did not significantly influence PA infection loads in mouse lungs.

STAT3 mRNA expression significantly decreased with lentivirus-mediated overexpression of SOCS3. p-STAT3 protein levels were also significantly downregulated in the lung tissue and $\mathrm{CD}^{+} \mathrm{T}$ cells under these conditions. Phosphorylated cascades of the JAK/STAT signaling pathway are associated with multiple biological processes in health and disease, including DNA binding, histone deacetylase recruiting and inflammatory development $(27,28)$. Therefore the negative effect of SOCS3 on inflammation may deregulate the expression and activation of STAT3. Shouda et al (29) and Suzuki et al (30) have reported that SOCS3 inhibits the STAT3 inflammatory pathway; furthermore, Chen et al (19) reported that SOCS3 is a major regulator of IL-23 mediated phosphorylation of STAT3, which binds directly to IL-17A and IL-17F promoters in CD4 ${ }^{+} \mathrm{T}$ cells. Additionally, STAT3 was observed to be a major regulator of Th17 responses, including Th17 differentiation and cytokine production (31). Accumulating evidence indicates that SOCS3 suppresses Th17 responses via STAT3, which is an important mediator of signaling transduction and inhibits airway inflammation in $\mathrm{CD}^{+} \mathrm{T}$ cells in the lungs.

IL-17A and IL- 8 are produced by Th17 cells, whilst ROR $\gamma \mathrm{t}$ and STAT3 act as important regulators during Th17 cell differentiation $(32,33)$. IL-17A is produced by activated Th17 cells in response to infected antigens $(34,35)$. Gram-negative bacteria appear to induce the expression of IL-17A via IL-23 and toll-like receptor 4-dependent signaling pathways $(36,37)$. In the present study, the percentage of IL-17A ${ }^{+}$cells and the levels of IL-17A and IL-8 mRNA were significantly decreased in $\mathrm{CD}^{+} \mathrm{T}$ cells following the upregulation of SOCS3. However, ROR $\gamma$ t mRNA expression significantly declined with increasing SOCS3 levels. These results suggest that SOCS3 may suppress Th17 responses by inhibiting ROR $\gamma \mathrm{t}$, which causes a decline in Th17 differentiation and production, thus limiting the proinflammatory contribution of STAT3 and p-STAT3 and attenuating PA-mediated inflammation.

In summary, overexpressed SOCS3 using lentivirus vectors significantly suppresses Th17 responses in alveolar $\mathrm{CD}^{+} \mathrm{T}$ cells by inhibiting the expression and activation of STAT3. These results indicate that SOCS3 and STAT3 may be potential targets for relieving airway inflammation during PA lung infection. 


\section{Acknowledgements}

The present study was supported by the National Natural Science Foundation of China (grant no. 81300005).

\section{Competing interests}

The authors declare that they have no competing interests.

\section{References}

1. Hengzhuang W, Song Z, Ciofu O, Onsøyen E, Rye PD and Høiby N OligoG CF-5/20 disruption of mucoid Pseudomonas aeruginosa biofilm in a murine lung infection model. Antimicrob Agents Chemother 60: 2620-2626, 2016.

2. Mayer-Hamblett N, Kloster M, Rosenfeld M, Gibson RL, Retsch-Bogart GZ, Emerson J, Thompson V and Ramsey BW: Impact of sustained eradication of new pseudomonas aeruginosa infection on long-term outcomes in cystic fibrosis. Clin Infect Dis 61: 707-715, 2015.

3. Sharma G, Rao S, Bansal A, Dang S, Gupta S and Gabrani R: Pseudomonas aeruginosa biofilm: Potential therapeutic targets. Biologicals 42: 1-7, 2014.

4. Darch SE, McNally A, Harrison F, Corander J, Barr HL, Paszkiewicz K, Holden S, Fogarty A, Crusz SA and Diggle SP: Recombination is a key driver of genomic and phenotypic diversity in a Pseudomonas aeruginosa population during cystic fibrosis infection. Sci Rep 5: 7649, 2015.

5. Armstrong DS, Hook SM, Jamsen KM, Nixon GM, Carzino R, Carlin JB, Robertson CF and Grimwood K: Lower airway inflammation in infants with cystic fibrosis detected by newborn screening. Pediatr Pulmonol 40: 500-510, 2005.

6. Regamey N, Tsartsali L, Hilliard TN, Fuchs O, Tan HL, Zhu J, Qiu YS, Alton EW, Jeffery PK, Bush A and Davies JC: Distinct patterns of inflammation in the airway lumen and bronchial mucosa of children with cystic fibrosis. Thorax 67: 164-170, 2012

7. Kolls JK: $\mathrm{CD}^{+}$T-cell subsets and host defense in the lung. Immunol Rev 252: 156-163, 2013.

8. Veldhoen M, Hocking RJ, Atkins CJ, Locksley RM and Stockinger B: TGFbeta in the context of an inflammatory cytokine milieu supports de novo differentiation of IL-17-producing T cells. Immunity 24: 179-189, 2006.

9. Mangan PR, Harrington LE, O'Quinn DB, Helms WS, Bullard DC, Elson CO, Hatton RD, Wahl SM, Schoeb TR and Weaver CT: Transforming growth factor- $\beta$ induces development of the $\mathrm{T}_{\mathrm{H}} 17$ lineage. Nature 441: 231-234, 2006.

10. Yang XO, Pappu BP, Nurieva R, Akimzhanov A, Kang HS, Chung Y Li M, Shah B, Panopoulos AD, Schluns KS, et al: T helper 17 lineage differentiation is programmed by orphan nuclear receptors ROR alpha and ROR gamma. Immunity 28: 29-39, 2008.

11. Ivanov II, Mckenzie BS, Liang Z, Tadokoro CE, Lepelley A, Lafaille JJ, Cua DJ and Littman DR: The orphan nuclear receptor RORgammat directs the differentiation program of proinflammatory IL-17 ${ }^{+}$T helper cells. Cell 126: 1121-1133, 2006.

12. Kolls JK and Lindén A: Interleukin-17 family members and inflammation. Immunity 21: 467-476, 2004.

13. Lubberts E: The role of IL-17 and family members in the pathogenesis of arthritis. Curr Opin Investig Drugs 4: 572-577, 2003.

14. Dubin PJ and Kolls JK: IL-23 mediates inflammatory responses to mucoid Pseudomonas aeruginosa lung infection in mice. Am J Physiol Lung Cell Mol Physiol 292: L519-L528, 2007.

15. Linossi EM, Babon JJ, Hilton DJ and Nicholson SE: Suppression of cytokine signaling: The SOCS prespective. Cytokine Growth Factor Rev 24: 241-248, 2013.

16. Yoshimura A and Yasukawa H: JAK's SOCS: A mechanism of inhibition. Immunity 36: 157-159, 2012.

17. Liu X,Ren S, QuX, GeC, Cheng K and Zhao RC: Mesenchymal stem cells inhibit Th17 cells differentiation via IFN- $\gamma$-mediated SOCS3 activation. Immunol Res 61: 219-229, 2015.

18. Tanaka K, Ichiyama K, Hashimoto M, Yoshida H, Takimoto T, Takaesu G, Torisu T, Hanada T, Yasukawa H, Fukuyama S, et al: Loss of suppressor of cytokine signaling 1 in helper T cells leads to defective Th17 differentiation by enhancing antagonistic effects of IFN-gamma on STAT3 and Smads. J Immunol 180: 3746-3756, 2008.
19. Chen Z, Laurence A, Kanno Y, Pacher-Zavisin M, Zhu BM, Tato C, Yoshimura A, Hennighausen L and O'Shea JJ: Selective regulatory function of Socs3 in the formation of IL-17-secreting T cells. Proc Natl Acad Sci USA 103: 8137-8142, 2006.

20. van Heeckeren AM and Schluchter MD: Murine models of chronic Pseudomonas aeruginosa lung infection. Lab Anim 36: 291-312, 2002.

21. Brown BD, Venneri MA,Zingale A, Sergi Sergi L and Naldini L: Endogenous microRNA regulation suppresses transgene expression in hematopoietic lineages and enables stable gene transfer. Nat Med 12: 585-591, 2006.

22. Livak KJ and Schmittgen TD: Analysis of relative gene expression data using real-time quantitative PCR and the $2^{-\Delta \Delta C_{\mathrm{T}}}$ method. Methods 25: 402-408, 2011.

23. Dalpke A and Heeg K: Suppressors of cytokine signaling proteins in innate and adaptive immune responses. Arch Immunol Ther Exp 51: 91-103, 2003.

24. Carow B and Rottenberg ME: SOCS3, a major regulator of infection and inflammation. Front Immunol 5: 58, 2014.

25. Khader SA, Pearl JE, Sakamoto K, Gilmartin L, Bell GK, Jelley-Gibbs DM, Ghilardi N, deSauvage F and Cooper AM: IL-23 compensates for the absence of IL-12p70 and is essential for the IL-17 response during tuberculosis but is dispensable for protection and antigen-specific IFN-gamma responses if IL-12p70 is available. J Immunol 175: 788-795, 2005.

26. Nguyen-Jackson H, Panopoulos AD, Zhang H, Li HS and Watowich SS: STAT3 controls the neutrophil migratory response to CXCR 2 ligands by direct activation of G-CSF-induced CXCR2 expression and via modulation of CXCR2 signal transduction. Blood 115: 3354-3363, 2010.

27. Xu D and Qu CK: Protein tyrosine phosphatases in the JAK/STAT pathway. Front Biosci 13: 4925-4932, 2008

28. Shuai K and Liu B: Regulation of JAK-STAT signalling in the immune system. Nat Rev Immunol 3: 900-911, 2003.

29. Shouda T, Yoshida T, Hanada T, Wakioka T, Oishi M, Miyoshi K, Komiya S, Kosai K, Hanakawa Y, Hashimoto K, et al: Induction of the cytokine signal regulator SOCS3/CIS3 as a therapeutic strategy for treating inflammatory arthritis. J Clin Invest 108: $1781-1788,2001$

30. Suzuki A, Hanada T, Mitsuyama K, Yoshida T, Kamizono S, Hoshino T, Kubo M, Yamashita A, Okabe M, Takeda K, et al: Cis3/Socs3/Ssi3 plays a negative regulatory role in STAT3 activation and intestinal inflammation. J Exp Med 193: 471-481, 2001.

31. Harris TJ, Grosso JF, Yen HR, Xin H, Kortylewski M, Albesiano E, Hipkiss EL, Getnet D, Goldberg MV, Maris CH, et al: Cutting edge: An in vivo requirement for STAT3 signaling in TH17 development and TH17-dependent autoimmunity. J Immunol 179: 4313-4317, 2007.

32. Ernst M, Najdovska M, Grail D, Lundgren-May T, Buchert M, Tye H, Matthews VB, Armes J, Bhathal PS, Hughes NR, et al: STAT3 and STAT1 mediate IL-11-dependent and inflammationassociated gastric tumorigenesis in gp130 receptor mutant mice. J Clin Invest 118: 1727-1738, 2008.

33. Brender C, Tannahill GM, Jenkins BJ, Fletcher J, Columbus R, Saris CJ, Ernst M, Nicola NA, Hilton DJ, Alexander WS and Starr R: Suppressor of cytokine signaling 3 regulates CD8 T-cell proliferation by inhibition of interleukins 6 and 27. Blood 110: 2528-2536, 2007

34. Moseley TA, Haudenschild DR, Rose L and Reddi AH: Interleukin-17 family and IL-17 receptors. Cytokine Growth Factor Rev 14: 155-174, 2003.

35. Ye P, Garvey PB, Zhang P, Nelson S, Bagby G, Summer WR, Schwarzenberger P, Shellito JE and Kolls JK: Interleukin-17 and lung host defense against Klebsiella pneumoniae infection. Am J Respir Cell Mol Biol 25: 335-340, 2001.

36. Happel KI, Zheng M, Young E, Quinton LJ, Lockhart E, Ramsay AJ, Shellito JE, Schurr JR, Bagby GJ, Nelson S and Kolls JK: Cutting edge: Roles of Toll-like receptor 4 and IL-23 in IL-17 expression in response to Klebsiella pneumoniae infection. J Immunol 170: 4432-4436, 2003.

37. Lindén A and Adachi M: Neutrophilic airway inflammation and IL-17. Allergy 57: 769-775, 2002. 